\title{
Promising inhibitors against main protease of SARS CoV-2 from medicinal plants: In silico identification
}

\author{
OLUWAKEMI EBENEZER* \\ MICHAEL SHAPI \\ Faculty of Natural Science \\ Department of Chemistry \\ Mangosuthu University of Technology \\ 511 Mangosuthu Highway, Durban \\ 4000, South Africa
}

\begin{abstract}
Some compounds reported as active against SARS CoV were selected, and docking studies were performed using the main protease of SARS CoV-2 as the receptor. The docked complex analysis shows that the ligands selectively bind with the target residues and binding affinity of amentoflavone $\left(-10.1 \mathrm{kcal} \mathrm{mol}^{-1}\right)$, isotheaflavin-3'-gallate $\left(-9.8 \mathrm{kcal} \mathrm{mol}^{-1}\right)$, tomentin $\mathrm{A}$ and $\mathrm{D}\left(-8.0\right.$ and $\left.-8.8 \mathrm{kcal} \mathrm{mol}^{-1}\right)$, theaflavin-3,3'-digallate $\left(-8.6 \mathrm{kcal} \mathrm{mol}^{-1}\right)$, papyriflavonol $\mathrm{A}\left(-8.4 \mathrm{kcal} \mathrm{mol}^{-1}\right)$, iguesterin $\left(-8.0 \mathrm{kcal} \mathrm{mol}^{-1}\right)$ and savinin $\left(-8.3 \mathrm{kcal} \mathrm{mol}^{-1}\right)$ were ranked above the binding affinity of the reference, co-crystal ligand, ML188, a furan-2-carboxamide-based compound. To pinpoint the drug-like compound among the top-ranked compounds, the Lipinski's rule of five and pharmacokinetic properties of all the selected compounds were evaluated. The results detailed that savinin exhibits high gastrointestinal absorption and can penetrate through the blood-brain barrier. Also, modifying these natural scaffolds with excellent binding affinity may lead to discovering of anti-SARS CoV agents with promising safety profiles.
\end{abstract}

Keywords: SARS CoV-2 main protease inhibitors, medicinal plants, molecular docking, ADMET properties

Coronavirus 2019 (COVID-19) is a new infectious disease that started as an epidemic in Wuhan, China, in December 2019. COVID-19 is caused by severe acute respiratory syndrome coronavirus 2 (SARS CoV-2) virus, a twin sister to SARS CoV. Although the two viruses are genetically and clinically different, they still share about $70-80 \%$ similarity in genome homology. In addition, closely to $96 \%$ of SARS CoV-2 genes are shared with the bat coronavirus (Bat-CoV) (1).

The genome of SARS CoV-2 consists of non-segmented RNA that includes $5^{\prime}$ and $3^{\prime}$ untranslated regions (UTRs), structural proteins and non-structural proteins. Structural and non-structural proteins in the virus genome are encoded in the open reading frames (ORFs) (1). The ORF1a and ORF1ab of several ORFs are proteolytically cleaved into 16 putative non-structural proteins (nsp1-16) for genome preservation and replicase complex development in viral replication $(2,3)$. Notably, the SARS CoV-2 genome is more stable than

\footnotetext{
*Correspondence; e-mail: ebenezer.oluwakemi@mut.ac.za
} 
SARS CoV or MERS-CoV. However, it generally mutates more rapidly, enabling evolutionary and genetic diversity. Thus, it results to alterations such as viral transmission, receptor affinity, host tropism, and pathogenicity compared to other RNA viruses (4). Its high transmissibility has led to the pandemic mentioned above, including global lock-down and adverse effects on global health $(2,4-6)$.

Numerous experts and pharmaceutical establishments are still conducting extensive research to appraise therapies for COVID-19 infection. As of August 24, 2021, there were 506 therapeutic drugs for COVID-19 at the development stage, 419 in human clinical trials and 87 in preclinical development. Interestingly, 53 therapeutic agents have reached clinical trial phase IV. In addition, 122 vaccines are in the phase of preclinical development and a total of 92 in human trials (7).

Modern medicine today utilizes active compounds isolated from higher plants, and about $80 \%$ of these show a positive correlation between their modern therapeutic use and the traditional uses (8). As well, the isolated compounds with activity against targets associated with SARS CoV infection could provide insights into drug development for the new anti-SARS CoV-2 agents. The prospect of using a computer-aided drug design (CADD) approach, which uses substantial computational power, has become one of the more effective methods to search for new lead compounds (9). In the continuation of the anti-SARS CoV-2 agents search, this article presents a molecular docking analysis of compounds isolated from medicinal plants with a high potency of anti-SARS CoV activity (10).

\section{EXPERIMENTAL}

\section{Ligand's selection}

Compounds used as ligands in the molecular docking procedure were selected based on their strong anti-SARS COV inhibiting activity (in vitro experiments) reported in the literature and recently reviewed by Ebenezer et al. (10). The most active compounds tested against SARS CoV proteases are detailed in Table I.

\section{Receptor selection}

The protease's X-ray crystal structure (PDB ID: 6LU7) was retrieved from the RCSB Protein Data Bank (23). Drugs that target conservative protease are usually capable of blocking the replication and proliferation of the virus simultaneously, reducing the risk of mutation-mediated drug resistance (24).

\section{Molecular docking}

Molecular docking simulations were performed to explore the binding profile of identified SARS CoV inhibitors at the binding site of SARS CoV-2 3CLpro. At the same time, Chem3D Ultra was used to construct the 3D geometry of identified compounds, followed by structure optimization. Subsequently, docking simulations were performed with the AutoDock 4.2 module implemented in PyRx 0.8 using the empirical free energy force field and Lamarckian genetic algorithm conformational search with default parameters. The grid coordinates for the protein's ligand-binding site were centered at $x=-20, y=13, z=47$, 
Table I. Compounds used for molecular docking studies

\begin{tabular}{|c|c|c|c|c|}
\hline Plant name & Family & $\begin{array}{l}\text { Plant part } \\
\text { studied }\end{array}$ & Isolated compound(s) & Ref. \\
\hline Tribulus terrestris & Zygophyllaceae & Fruits & Terrestrimine & 11 \\
\hline Isatis indigotica & Brassicaceae & Root & Sinigrin, hesperetin & 12 \\
\hline Salvia miltiorrhiza & Lamiaceae & Root & $\begin{array}{l}\text { Cryptotanshinone, dihydrotan- } \\
\text { shinone } 1\end{array}$ & 13 \\
\hline Angelica keiskei & Apiaceae & Leaves & Isobavachalcone, xanthoangelol & 14 \\
\hline Broussonetia papyrifera & Moraceae & Root & Papyriflavonol A & 15 \\
\hline Torreya nucifera & Taxaceae & Leaves & Amentoflavone & 16 \\
\hline Psoralea corylifolia & Fabaceae & Seeds & Psoralidin, isobavachalcone & 17 \\
\hline Alnus japonica & Betulaceae & Stem bark & Hirsutenone & 18 \\
\hline Tripterygium regelii & Celastraceae & Bark & Iguesterin & 19 \\
\hline $\begin{array}{l}\text { Green tea (Camellia } \\
\text { sinensis) }\end{array}$ & Theaceae & Leaves & $\begin{array}{l}\text { Theaflavin-3,3'-digallate (TF3), } \\
\text { isotheaflavin-3'-gallate (TF2B), etc. }\end{array}$ & 20 \\
\hline Paulownia tomentosa & Paulowniaceae & Fruits & Tomentin A-E & 21 \\
\hline Chamaecyparis obtuse & Cupressaceae & Heartwood & Savinin & 22 \\
\hline
\end{tabular}

while grid dimensions were set at $40 \times 30 \times 62 \AA(25)$. The complex's grid box had a grid spacing of $0.375 \AA$. Analysis and visualization of the binding interactions in the protein-ligand complex were achieved using Discovery Studio Visualizer.

Additionally, the physico-chemical and ADME properties of the docked compounds were computed with SwissADME web-based tool (26).

\section{RESULTS AND DISCUSSION}

Before simulating the binding interactions of the active compounds detailed in Table I with SARS CoV-2 3CLpro, a reliable docking model was first created using ML188, a furan-2-carboxamide-based and non-covalent inhibitor of SARS CoV 3CLpro. ML188 is bound tightly to the SARS CoV-2 3CLpro receptor with a binding affinity (BA) of $-7.7 \mathrm{kcal} \mathrm{mol}^{-1}$.

The ML188, a furan-2-carboxamide-based compound which is the co-crystal ligand formed hydrogen bond with the Cys145-His41 catalytic dyad alongside hydrophobic interaction with other active site residues such as Thr24, Thr25, Phe140, Gly143 and Pro168. Interestingly, similar binding profiles were observed with the docked compounds; amentoflavone displayed the tightest binding overall. ADME profiling of amentoflavone also suggested that it possesses desirable drug-like properties for good oral bioavailability and plasma distribution. The computed PAIN (Pan-assay interference compounds) alert indicates that all the compounds as shown in Table II (except isotheaflavin-3'-gallate, theaflavin-3,3'-digallate, dihydrotanshinone 1, xanthoangelol and hirsutenone) are non-promiscuous drug candidates, i.e., they are target specific. 


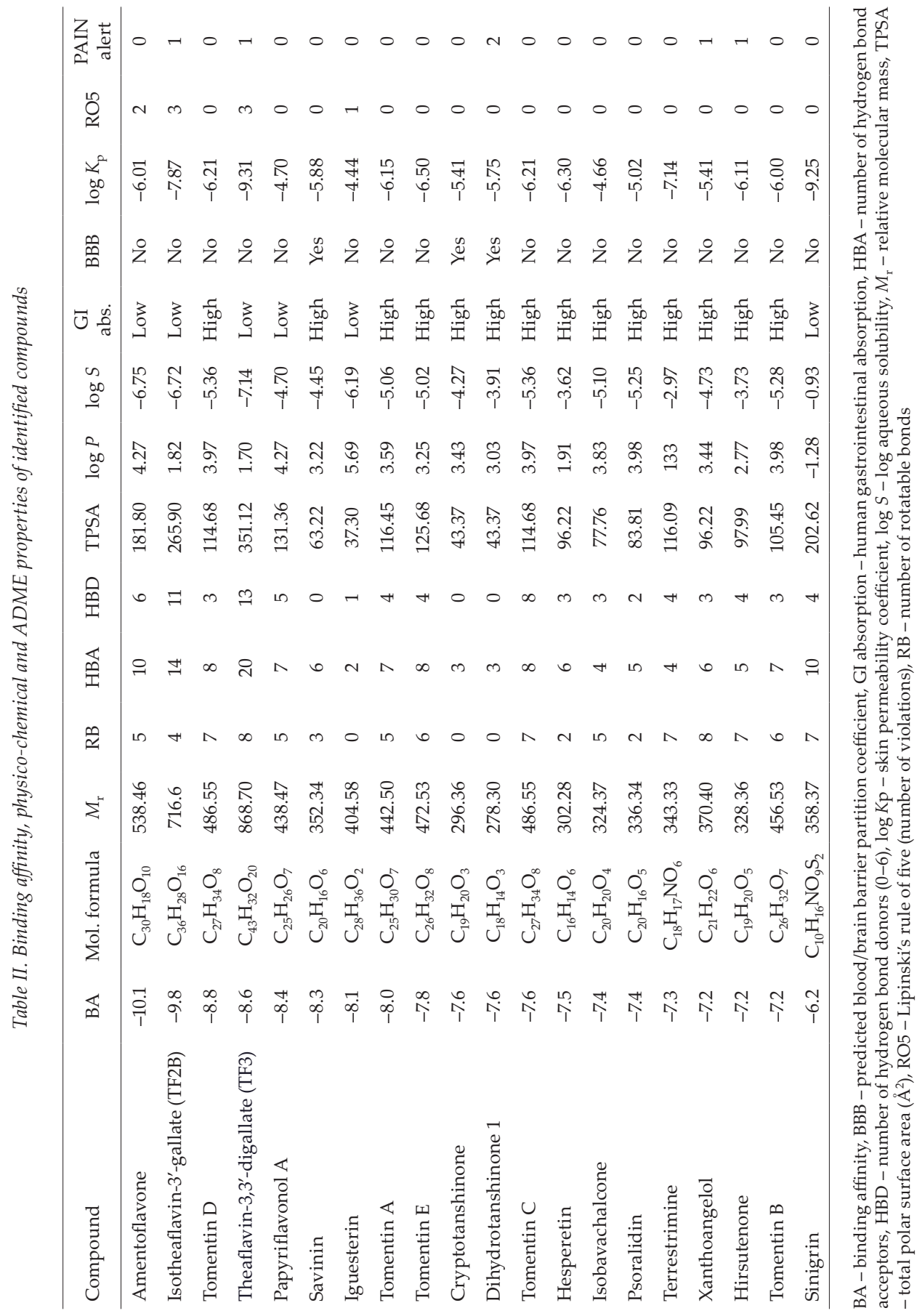




\section{Binding interactions of COVID-19 main protease with potentially active compounds}

Papyriflavonol A. - Our docking simulation of papyriflavonol A suggests that hydrogen bond interactions of chromenone core with Glu166, and hydroxyl units of ring B with Gly143, Ser144 and key residue Cys145, resp., might be crucial for potent protease inhibition (Fig. 1a). Also, hydrophobic interactions with His163, Met165, Pro168 and Gly189, presumably stabilized the protein-ligand complex in the binding pocket. The physico-chemical properties show that papyriflavonol A has the potential to be used as a drug. Besides, the total polar surface area (TPSA) of papyriflavonol A is $131.36 \AA^{2}$ which indicates an excellent value for bioavailability of potential drug candidate.

Amentoflavone. - The absence of methoxy groups in amentoflavone molecule seems to favor its inhibitory potency, reflected in the compound's superior binding affinity $(-10.1$ $\mathrm{kcal} \mathrm{mol}^{-1}$ ) at SARS CoV-2 3CLpro active site. Significant interactions in the amentoflavone-3CLpro complex include H-bonding of chromenone hydroxy group and oxygen atom with Thr26 and Glu166, resp., and ring B hydroxy group with Tyr54 amino acid (Fig. 1b). The catalytic dyad (Cys145-His41) is also sandwiched between the chromenone cores via hydrophobic contact and H-bond and T-shaped $\pi-\pi$ stacking interactions with phenoxy linker and ring B,

a)

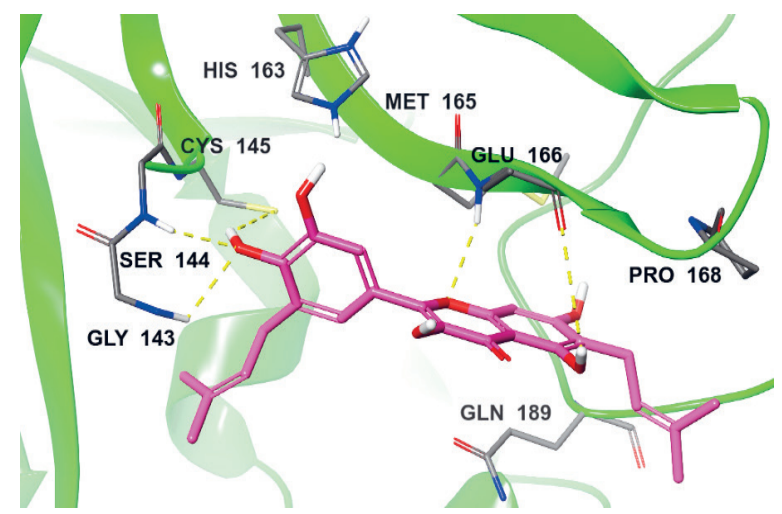

b)

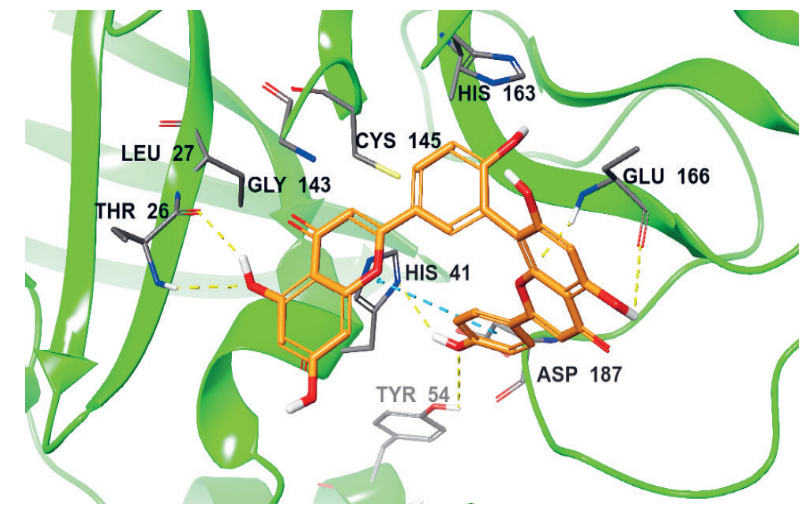

Fig. 1. Binding interactions of: a) papyriflavonol A and b) amentoflavone with active site residues of SARS CoV-2 3CLpro. 
resp. Similar hydrophobic contacts exist with Leu27, Gly143, His163 and Asp187. It is worth mentioning that the increase in the molecular mass and hydrogen bond acceptors of amentoflavone compared to papyriflavonol A have a significant impact on the compound bioavailability. Amentoflavone has a molecular mass > 500 and the TPSA is $>140 \AA^{2}$ (Table II).

Iguesterin. - Molecular docking of iguesterin in the substrate-binding pocket of SARS CoV-2 3CLpro presented H-bond interaction of hydroxyl group with Cys145 and Glu166 (bond distance $=3.01$ and $2.92 \AA^{2}$, resp.), and hydrophobic interaction with Pro168 and Ala191. The presence of a quinone-methide moiety plays a significant role in the inhibitory potency of iguesterin and its interaction with drug targets. The TPSA was found to be 37.30 $\AA^{2}$ which is far less than $140 \AA^{2}$, as shown in Table II, thus predicting that iguesterin has better membrane permeability than amentoflavone. Namely, the molecules with TPSA $\geq$ $140 \AA^{2}$ show a low ability for penetrating cell membranes, while docked compounds with TPSA $\leq 60 \AA^{2}$ are easily absorbed in the cell membranes.

Isotheaflavin-3'-gallate and theaflavin-3,3'-digallate. - Our molecular docking studies showed that isotheaflavin-3'-gallate (TF2B) and theaflavin-3,3'-digallate (TF3) fitted better in the binding pocket of SARS CoV-2 3CLpro compared to tannic acid. A detailed analysis

a)

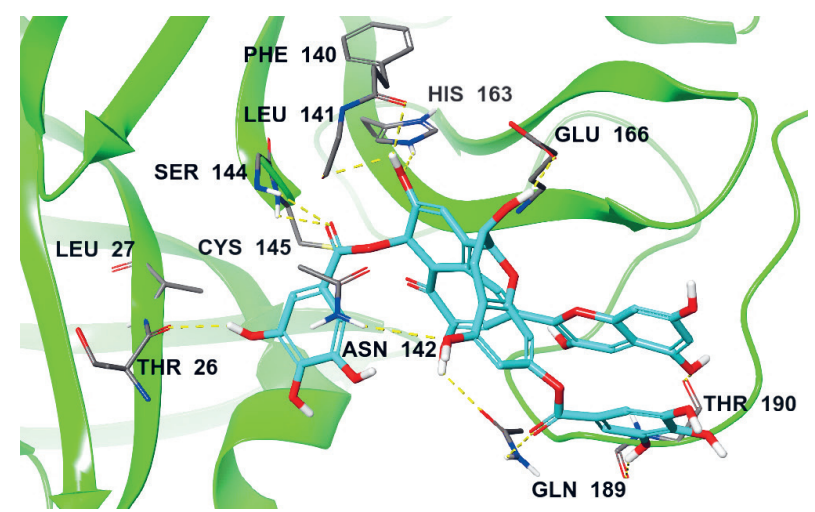

b)

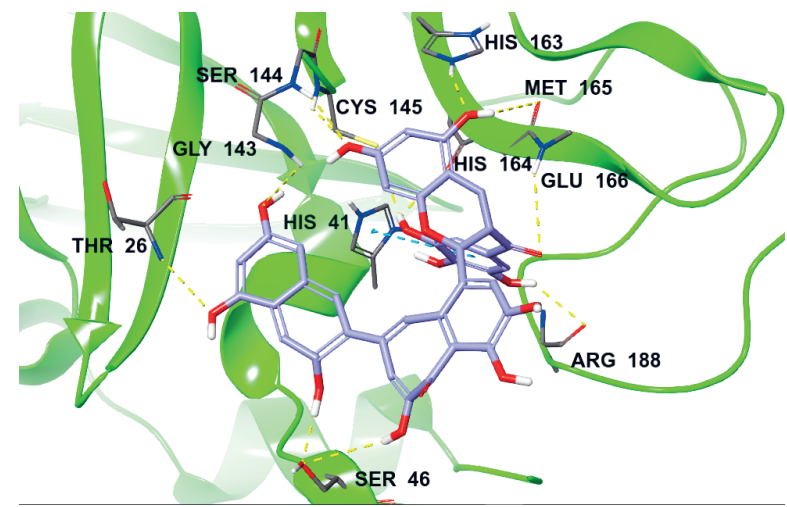

Fig. 2. Binding interactions of: a) isotheaflavin-3'-gallate (TF2B) and b) theaflavin-3,3'-digallate (TF3) at the active site pocket of SARS CoV-2 3CLpro. 
of the inhibitors' binding profile (Fig. 2a) established the dominance of H-bond interactions, particularly between hydroxy units and Thr26, Phe140, Leu141, Asn142, His163, Glu166, Gln189 and Thr190. Ser144 and Gln189 also interacted in the like manner with the carbonyl oxygen atoms of 3,4,5-trihydroxybenzoate moieties. On the other hand, TF2B scaffold featured an identical binding profile with TF3, albeit with additional H-bond interactions of trihydroxy substituted ring-B with Cys145 and Met165 together with a T-shaped $\pi-\pi$ stacking interaction with His41, which might favor inhibitory potency against SARS CoV-2 3CLpro (Fig. 2b). Moreover, it is reasonable to assume that the hydrophobic contacts of TF2B with His41 and Met165 helped stabilize the protein-ligand complex and contributed to the increased binding affinity recorded (Fig. 2b). Interestingly, the physico-chemical predictions detailed that TF2B and TF3 violate the rule of five which is not surprising due to their similar functional groups and structural skeletons. The compounds have high molecular mass, as shown in Table II, whereas the pharmacokinetics prediction showed incapacity of the compounds to pass through the blood-brain barrier, thus presumably not be suitable for drug development.

Tomentin A and tomentin D. - Molecular modeling of the SARS CoV-2 complex of tomentin $\mathrm{A}$ and $\mathrm{D}$ revealed that both compounds could form hydrophobic interactions with the

a)

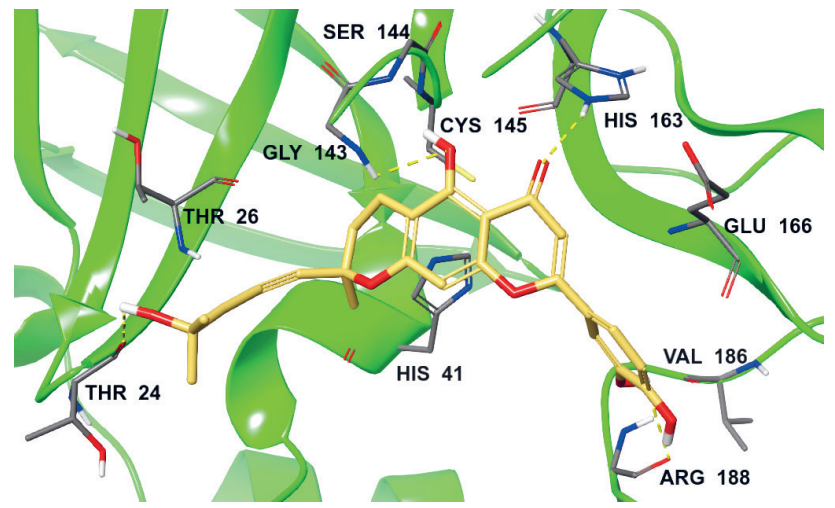

b)

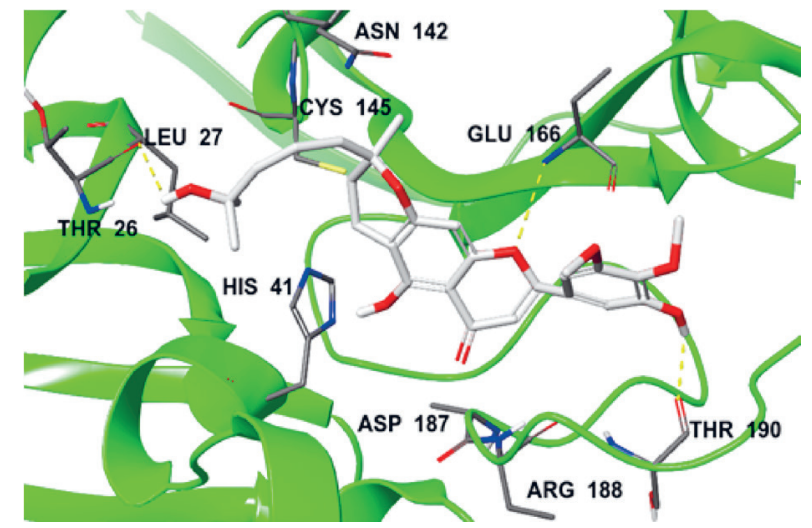

Fig. 3. Binding interaction of: a) tomentin A and b) tomentin D at the active pocket of SARS CoV 3CLpro. 


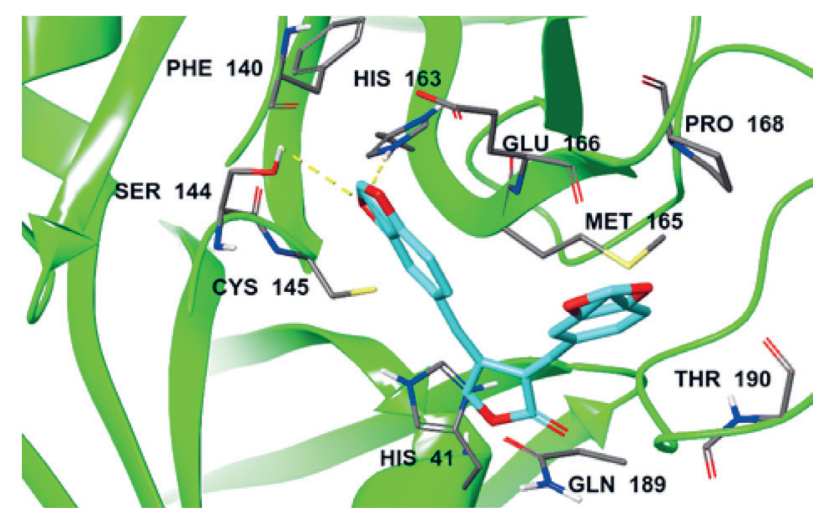

Fig. 4. Binding interaction of savinin with residues in the active pocket of SARS CoV-2 3CLpro.

catalytic dyad - Cys145-His41 (Fig. 3). Precisely, tomentin A-3CLpro complex featured H-bond interactions with Thr24 and Gly143 via the hydroxyl units of 2-methylhex-3-en-2-ol pendant and ring-A, resp. (Fig. 3a). The chromenone carbonyl oxygen and the ring-B hydroxy unit also form H-bonds to His168 and Arg188, resp., whereas the complex is possibly stabilized by hydrophobic contacts with residues Thr26, Glu166 and Val188.

In parallel, the hydroxyl unit of alkanol pendant in tomentin D also forms H-bonds with the amine group of Thr26 while the endocyclic chromenone oxygen and methoxy group of ring-B are involved in similar H-bond interactions with Glu166 and Thr190, resp. (Fig. 3b). The $M_{\mathrm{r}^{\prime}} \log P$, and TPSA of tomentin A varied from that of tomentin D as shown in Table II. There were no significant differences in the skin permeability, through $\log K_{p}$ values, and the two compounds followed Lipinski's rule of five. In addition, tomentin A and D have a high probability of oral bioavailability without pain alert; hence they are good candidates for the drug development.

Savinin. - Savinin is lignoid which exhibited more potent anti-SARS CoV effects than ferruginol, dehydroabieta-7-one, sugiol, 8-hydroxyabieta-9(11),13-dien-12-one, 6,7-dehydroroyleanone, pinusolidic acid and R-cadinol, with an $I C_{50}$ of $25 \mu \mathrm{mol} \mathrm{L}{ }^{-1}$. The visual studies showed H-bond interactions of benzo[1,3]dioxole fragment with Ser144 and His163, as well as the ligand's stable conformation in the binding pocket through hydrophobic contacts with residues such as Cys145, His41, Phe140, Met165 and Glu166 (Fig. 4). These significant interactions will aid the SARS CoV-2 inhibitory activity of savinin. Interestingly, the compound complied with most drug-like indices; the predicted lead compound tends to be drug-like. Savinin is expected to cross the blood-brain barrier (Table II); meanwhile, its human gastrointestinal absorption might be also high.

\section{CONCLUSIONS}

In this study, we performed molecular docking using COVID-19 main protease on some selected active compounds isolated from medicinal plants. These compounds have been reported to inhibit SARS CoV activity. The docked complex analysis shows that the ligands selectively bind with the target residues, and binding affinity of amentoflavone 
$\left(-10.1 \mathrm{kcal} \mathrm{mol}^{-1}\right)$, isotheaflavin-3'-gallate $\left(-9.8 \mathrm{kcal} \mathrm{mol}^{-1}\right)$, tomentin A and D $(-8.0$ and -8.8 kcal mol$\left.{ }^{-1}\right)$, theaflavin-3,3'-digallate $\left(-8.6 \mathrm{kcal} \mathrm{mol}^{-1}\right)$, papyriflavonol A $\left(-8.4 \mathrm{kcal} \mathrm{mol}^{-1}\right)$, iguesterin $\left(-8.0 \mathrm{kcal} \mathrm{mol}^{-1}\right)$ and savinin $\left(-8.3 \mathrm{kcal} \mathrm{mol}^{-1}\right)$ were ranked above the binding affinity of the native ligand. The pharmacokinetics predictions detailed that savinin extracted from Chamaecyparis obtuse might exhibit high gastrointestinal absorption and probably penetrate through the blood-brain barrier. Also, modifying these natural scaffolds that have an excellent binding affinity may lead to discovery of novel drug-like candidates.

Abbreviations, acronyms, codes. - CADD - computer-aided drug design, 3CLpro - 3C-like protease, Nsp - non-structural proteins, ORFs - open reading frames, $\mathrm{PDB}$ - protein data bank, RO5 - rule of five, SARS- $\mathrm{CoV}$ - severe acute respiratory syndrome coronavirus, TF2B - isotheaflavin-3'-gallate, TF3 - theaflavin-3,3'-digallate, TPSA - total polar surface area, UTRs - untranslated regions

Acknowledgments. - The authors thank the Mangosuthu University of Technology (MUT) for financial assistance. They would also like to thank the anonymous reviewers and the Editor-in-chief for providing extensive corrections and suggestions for the quality improvement of this work.

\section{REFERENCES}

1. A. Rahimi, A. Mirzazadeh and S. Tavakolpour, Genetics and genomics of SARS CoV-2: A review of the literature with the special focus on genetic diversity and SARS CoV-2 genome detection, Genomics 113 (2021) 1221-1232; https://doi.org/10.1016/j.ygeno.2020.09.059

2. Y. A. Helmy, M. Fawzy, A. Elaswad, A. Sobieh, S. P. Kenney and A. A. Shehata, The COVID-19 pandemic: A comprehensive review of taxonomy, genetics, epidemiology, diagnosis, treatment, and control, J. Clin. Med. 9 (2020) Article ID 1225; https://doi.org/10.3390/jcm9041225

3. D. E. Gordon, G. M. Jang, M. Bouhaddou, J. Xu, K. Obernier, K. M. White, M. J. O'Meara, V. V. Rezelj, J. Z. Guo, D. L. Swaney, T. A. Tummino, R. Hüttenhain, R. M. Kaake, A. L. Richards, B. Tutuncuoglu, H. Foussard, J. Batra, K. Haas, M. Modak, M. Kim, P. Haas, B. J. Polacco, H. Braberg, J. M. Fabius, M. Eckhardt, M. Soucheray, M. J. Bennett, M. Cakir, M. J. McGregor, Q. Li, B. Meyer, F. Roesch, T. Vallet, A. Mac Kain, L. Miorin, E. Moreno, Z. Z. Chi Naing, Y. Zhou, S. Peng, Y. Shi, Z. Zhang, W. Shen, I. T. Kirby, J. E. Melnyk, J. S. Chorba, K. Lou, S. A. Dai, I. Barrio-Hernandez, D. Memon, C. Hernandez-Armenta, J. Lyu, C. J. P. Mathy, T. Perica, K. B. Pilla, S. J. Ganesan, D. J. Saltzberg, R. Rakesh, X. Liu, S. B. Rosenthal, L. Calviello, S. Venkataramanan, J. Liboy-Lugo, Y. Lin, X.-P. Huang, Y. F. Liu, S. A. Wankowicz, M. Bohn, M. Safari, F. S. Ugur, C. Koh, N. S. Savar, Q. D. Tran, D. Shengjuler, S. J. Fletcher, M. C. O’Neal, Y. Cai, J. C. J. Chang, D. J. Broadhurst, S. Klippsten, P. P. Sharp, N. A. Wenzell, D. Kuzuoglu-Ozturk, H.-Y. Wang, R. Trenker, J. M. Young, D. A. Cavero, J. Hiatt, T. L. Roth, U. Rathore, A. Subramanian, J. Noack, M. Hubert, R. M. Stroud, A. D. Frankel, O. S. Rosenberg, K. A. Verba, D. A. Agard, M. Ott, M. Emerman, N. Jura, M. von Zastrow, E. Verdin, A. Ashworth, O. Schwartz, C. d'Enfert, S. Mukherjee, M. Jacobson, H. S. Malik, D. G. Fujimori, T. Ideker, C. S. Craik, S. N. Floor, J. S. Fraser, J. D. Gross, A. Sali, B. L. Roth, D. Ruggero, J. Taunton, T. Kortemme, P. Beltrao, M. Vignuzzi, A. García-Sastre, K. M. Shokat, B. K. Shoichet, N. J. Krogan, A SARS-CoV-2 protein interaction map reveals targets for drug repurposing, Nature 583 (2020) 459-468; https://doi.org/ 10.1038/s41586-020-2286-9

4. J.-S. Kim, J. Jang, J. Kim, Y. Chung, C. Yoo and M. Han, Genome-wide identification and characterization of point mutations in the SARS CoV-2 genome, Osong Public Health Res. Perspect. 11 (2020) 101-111; https://doi.org/10.24171/j.phrp.2020.11.3

5. M. Rastogi, N. Pandey, A. Shukla and S. K. Singh, SARS coronavirus 2:From genome to infectome, Respir. Res. 21 (2020) Article ID 318; https://doi.org/10.1186/s12931-020-01581-z 
6. Q. Li, X. Guan, P. Wu, X. Wang, L. Zhou, Y. Tong, R. Ren, K. Leung, E. Lau, J. Wong, X. Xing, N. Xiang, Y. Wu, C. Li, Q. Chen, D. Li, T. Liu, J. Zhao, M. Liu, W. Tu and Z. Feng, Early transmission dynamics in Wuhan, China, of novel coronavirus-infected pneumonia, N. Engl. J. Med. 382 (2020) 1199-1207; https://doi.org/10.1056/NEJMoa2001316

7. COVID-19 Vaccine $\mathcal{E}$ Therapeutics Tracker; https://biorender.com/covid-vaccine-tracker; last access date August 5, 2021

8. A. N. M. Alamgir, Pharmacognostical Botany: Classification of Medicinal and Aromatic Plants (Maps), in Pharmacognostical Botany, Botanical Taxonomy, Morphology, and Anatomy of Drug Plants, in Therapeutic Use of Medicinal Plants and Their Extracts, Vol. 1, Springer International Publishing AG, Cham (Switzerland), 2017, pp. 177-293.

9. O. Ebenezer, M. A. Jordaan, N. Damoyi and M. Shapi, Discovery of potential inhibitors for RNAdependent RNA polymerase of norovirus: Virtual screening, and molecular dynamics, Int. J. Mol. Sci. 22 (2021) Article ID 171 (24 pages); https://doi.org/10.3390/ijms22010171

10. O. Ebenezer, O. Bodede, P. Awolade, M. A. Jordaan, R. E. Ogunsakin and M. Shapi, Medicinal plants with anti-SARS-CoV activity repurposing for treatment of COVID-19 infection: A systematic review and meta-analysis, Acta Pharm. 72 (2022) 199-224; https://doi.org/10.2478/acph-2022-0021

11. Y. H. Song, D. W. Kim, M. J. Curtis-Long, H. J. Yuk, Y. Wang, N. Zhuang, K. H. Lee, K. S. Jeon and K. H. Park, Papain-like protease (PLpro) inhibitory effects of cinnamic amides from Tribulus terrestris fruits, Biol. Pharm. Bull. 37 (2014) 1021-1028; https://doi.org/10.1248/bpb.b14-00026

12. C.-W. Lin, F.-J. Tsai, C.-H. Tsai, C.-C. Lai, L. Wan, T.-Y. Ho, C.-C. Hsieh and P.-D. L. Chao, AntiSARS coronavirus 3C-like protease effects of Isatis indigotica root and plant-derived phenolic compounds, Antiviral Res. 68 (2005) 36-42; https://doi.org/10.1016/j.antiviral.2005.07.002

13. Y. Park, H. Kim, M. Kim, J. Jeong, W. Kim, H. Park, J. Kwon, J. Park, S. Lee and B Ryu, Tanshinones as selective and slow-binding inhibitorsFor SARS CoV cysteine proteases, Bioorg. Med. Chem. 20 (2012) 5928-5935; https://doi.org/10.1016/j.bmc.2012.07.03

14. Y. Park, H. Kim, M. Kim, J. Jeong, W. Kim, H. Park, J. Kwon, J. Park, S. Lee and B. Ryu, Chalcones isolated from Angelica keiskei inhibit cysteine proteases of SARS CoV, J. Enzyme Inhib. Med. Chem. 31 (2016) 23-30; https://doi.org/10.3109/14756366.2014.1003215

15. S. Jo, S. Kim, H. Shin and S. Kim, Inhibition of SARS CoV 3CL protease byFlavonoids, J. Enzyme Inhib. Med. Chem. 35 (2020) 145-151; https://doi.org/10.1080/14756366.2019.1690480

16. B. Ryu, H. Jeong, H. Kim, M. Kim, Y. Park, D. Kim, T. Nguyen, J. Park, S. Chang, H. Park, C. Rho and S. Lee, Biflavonoids from Torreya nucifera displaying SARS CoV 3CL(pro) inhibition, Bioorg. Med. Chem. 18 (2010) 7940-7947; https://doi.org/10.1016/j.bmc.2010.09.03517

17. W. Kim, H. Seo, J. Curtis-Long, Y. Oh, W. Oh, K. Cho, H. Lee and H. Park, Phenolic phytochemical displaying SARS CoV papain-like protease inhibition from the seeds of Psoralea corylifolia, J. Enzyme Inhib. Med. Chem. 29 (2014) 59-63; https://doi.org/10.3109/14756366.2012.75359118

18. J.-Y. Park, H. J. Jeong, J. H. Kim, Y. M. Kim, S.-J. Park, D. Kim, K. H. Park, W. S. Lee and Y. B. Ryu, Diarylheptanoids from Alnus japonica inhibit papain-like protease of severe acute respiratory syndrome coronavirus, Biol. Pharm. Bull. 35 (2012) 2036-2042; https://doi.org/10.1248/bpb.b12-00623

19. B. Ryu, J. Park, M. Kim, Y. Lee, D. Seo, S. Chang, H. Park, C. Rhoand and S. Lee, SARS CoV 3CLpro inhibitory effects of quinone-methide triterpenes from Tripterygium regelii, Bioorg. Med. Chem. Lett. 20 (2010) 1873-1876; https://doi.org/10.1016/j.bmcl.2010.01.15220

20. N. Chen, P. Lin, K. Huang, C. Chen, P. Hsieh, H. Liang and T. Hsu, Inhibition of SARS CoV 3C-like protease activity by theaflavin-3,3'-digallate (TF3), Evid. Based Complement. Alternat. Med. 2 (2005) 209-215; https://doi.org/10.1093/ecam/neh081

21. J. Cho, J. Curtis-Long, H. Lee, D. Kim, W. Ryu, J. Yuk and H. Park, Geranylated Flavonoids displaying SARS CoV papain-like protease inhibition from the fruits of Paulownia tomentosa, Bioorg. Med. Chem. 21 (2013) 3051-3057; https://doi.org/10.1016/j.bmc.2013.03.02722 
22. C.-C. Wen, Y.-H. Kuo, J.-T. Jan, P.-H. Liang, S.-Y. Wang, H.-G. Liu, C.-K. Lee, S.-T. Chang, C.-J. Kuo, S.-S. Lee, C.-C. Hou, P.-W. Hsiao, S.-C. Chien, L.-F. Shyur and N. S. Yang, Specific plant terpenoids and lignoids possess potent antiviral activities against severe acute respiratory syndrome coronavirus, J. Med. Chem. 50 (2007) 4087-4095; https://doi.org/10.1021/jm070295s

23. Z. Jin, X. Du, Y. Xu, Y. Deng, M. Liu, Y. Zhao, B. Zhang, X. Li, L. Zhang, C. Peng, Y. Duan, J. Yu, L. Wang, K. Yang, F. Liu, R. Jiang, X. Yang, T. You, X. Liu, X. Yang, F. Bai, H. Liu, X. Liu, L. W. Guddat, W. Xu, G. Xiao, C. Qin, Z. Shi, H. Jiang, Z. Rao and H. Yang, Structure of MproFrom SARS-CoV-2 and discovery of its inhibitors, Nature 582 (2020) 289-293; https://doi.org/10.1038/s41586-020-2223-y

24. A. Jordaan, O. Ebenezer, N. Damoyi and M. Shapi, Virtual screening, molecular docking studies and DFT calculations of FDA approved compounds similar to the non-nucleoside reverse transcriptase inhibitor (NNRTI) efavirenz, Heliyon 6 (2020) e04642; https://doi.org/10.1016/j.heliyon.2020.e0464225

25. O. Trott and J. Olson, AutoDock Vina: improving the speed and accuracy of docking with a new scoringFunction, efficient optimization, and multithreading, J. Comput. Chem. 31 (2010) 455-461; https://doi.org/10.1002/jcc.21334

26. A. Daina, O. Michielin and V. Zoete, SwissADME: aFree web tool to evaluate pharmacokinetics, drug-likeness and medicinal chemistryFriendliness of small molecules, Sci. Rep. 7 (2017) Article ID 42717; https://doi.org/10.1038/srep42717 